\title{
A System of Spiritual Education in the Traditional and Pedagogical Culture of Kazakh Family
}

\author{
M. D. Yesekeshova \\ Ph.D. Professor of PAE, APOC Corresponding Member, Associate professor, S. Seifullin Kazakh Agro Technical University \\ Lecturer, 010000, Astana, Kazakhstan; Email: idt12@mail.ru
}

\section{Doi:10.5901/jesr.2015.v5n3p263}

\begin{abstract}
The article explains the formation and development of the traditional pedagogical culture of Kazakh people and long history of education. This article considers the development of teacher's consciousness of the people as an inseparable part of the social, historical, and cultural content of the traditional pedagogical culture. The educating of moral values in Kazakh family and as well as the process of upbringing morality in traditional-pedagogical culture of the Kazakh family are taken into consideration. The system of traditional moral upbringing in the Kazakh family is the aim to be proved and the object to be experimentally studied along with systematizing it and using it in continuous education providing tutorials. The conclusion and the results of the study education of young people are given in the article of moral.
\end{abstract}

Keywords: culture, analysis, history, upbringing, tradition, methods

\section{Introduction}

The formation and development of traditional pedagogical culture, as well as education and the development of pedagogical thinking, cannot be explained without social, historical, and cultural intention. This belief has strong relations to Kazakh people.

If one does not consider the national and cultural property, as well as research its consequence, there is bound to a negative effect on the development of the national philosophy in the future. The President of the Republic of Kazakhstan, N. A. Nazarbayev, stated that economical, political, national, ecological, and spiritual crisis appear after economic reforms, and will bear an influence on the societal development progress for younger generations. So, it is apparent that the lack of human spirits may lead to social crisis. Upbringing of young people is very important for the future of our state and the formation of national spirit and spiritual qualities [Yesekeshova M. 2003].

President Nazarbayev also said that "unique ethical and psychological world of Kazakhs is the science that has not been studied yet." Remembering the past and rehabilitation of historical truth is the requirements of a modern society because it can influence the formation and development of personal qualities by relating to the inner spiritual world of young people. Development of society and its historical and pedagogical analysis unwittingly leads to the idea that culture is a system of continuous, permanent collection of tradition interactions and novelties [Yesekeshova M. 2005].

Culture is not destruction but a creation. Culture is the source from which every nation derives on the path of development and prosperity. There is always a close relationship between livelihood of the people, their chosen destination, and source of culture.

Culture emerges from such values of the society as language, education, traditions, and art over time and turned into the custom of this society, each of which is a very important collection of basics.

Not paying attention to these basics is blindness; distancing them from the society denies its direction, and people devoid of culture disappear by drowning in its ignorance.

Culture, as a result of interaction between the peoples, can move from one society to another. However, if their transition "fans" of the national spirit will do work properly during, unacceptable elements will not be discarded, and culture and civilization will be at an impasse.

The real culture is boiled in a cauldron of scientists soaking up the true faith, exemplary, and mind. We cannot talk about culture in a place where there is no religion, morals, and ignorance.

To be related to other nation's culture and civilization and to think of flourishing one's national future is like looking at the grass on the other side of the fence. At the same time, it is ridiculous and absurd. Culture is born in the cradle of the nation and society. 
Our president, N.A. Nazarbayev, mentioned in his works about the obligation of returning to Kazakh customs and traditions: "we need to pay attention to the tradition, the deep foundations of conscience and spirituality in the life of every nation. Its role is undeniable in the lives of the people. Cultural traditions have always been the key to social transformation. Returning to historical and cultural roots is certainly a positive process" (Education Act of Republic of Kazakhstan (1992).

Academician M. Kozybaev also wrote that every nation honors its history, customs, traditions, literature, and language. This means that if the nation cannot maintain its cultural and spiritual values, it will not be able to resist external cultural and spiritual predatory attacks. Such king of nation could not preserve its statehood.

In Kazakh folk pedagogy education of conscientiousness in parenting is the basis for forming humanity in Kazakh families as described by Kazakh philosophers such as A. Derbesaly, A. Aitaly, G. Esim. Kazakh Al-Farabi, Zh. Balasaguni, Korkytata, a teacher-educator Sh. Ualikhanov, Y. Altynsarin, A. Kunanbayev, Sh. Kudaiberdiev, A. Baitursynov, M. Zhumabayev, Zh. Aimautov, etc.

The main ethno-pedagogical issues in Kazakhstan were considered by A. Sembayev, K. Berzhanov, S. Gabbasov, I. Khalitova, A. Abilkasymova, R. Omarova, A.Seiteshov, B. Momynbayey, B. Abdikarimuly, O. Omar, M. Sarybekov, L. Baisarke, etc.

Various aspects of the theory of pedagogy and classroom practice as humanity, patriotism, aesthetics, and labor were described in the works of B. Mukanova, R. Toleubekova, S. Uzakbayeva, and K. Shalgynbayeva. Also, G. Volkov, K. Zharykbayev, A. Tabyldiev, T. Alsatov, K. Boleev, K. Kozhakhmetova, Zh. Sarybekova, Zh. Asanov, R. Duysembinova remembered the forming of ethno pedagogics as a science [Nazarbayev, N. A. 2005].

One of the main objectives of the public program is forming the whole system of remembering "cultural legacy," including modern national culture, literature, customs, and traditions.

Kazakh people, especially in western Kazakhstan, have traditions as respecting the old, honoring the elder, being kind to children, protecting the youth, reverencing parents, and cherishing women.

Kazakh people have traditions passing down from ancient years. These traditions as unwritten laws have deep roots. We have to respect, native language, and religion. Happiness, honor, wealth, and strength of our people are included in them. We have no stable future without them. To be conscientious means to have the ability to preserve traditions, to respect and care about the fate of generations.

There are a lot of rituals and traditions that a person must follow during their lifetime. No matter what the social order was, a family and marriage were decisive factors in the history of human development because they supplied bearing and growth of human beings.

"Man continues living in his popularity" is offspring wisdom. And, of course, here it implies being healthy, both physically and psychologically.

This topic was chosen because of the failure in educating a sense of conscience in continuing education of the young people. We took as an issue the ways of solving the problems of these contradictions. Nevertheless, the research question based on the scientific concept "Traditional pedagogical education of consciousness in Kazakh families" requires studying the theoretical side and checking the practical side. Thus, we chose the title as "A system of educating of conscience in traditional pedagogical culture of Kazakh families" [ Boleev K. (1992).].

Research Objective: The spiritual upbringing in Kazakh family is researched out.

Research Subject: The experience of teenagers' spiritual upbringing in Kazakh family.

Research Aim: To define main types of spiritual upbringing in Kazakh family, to systematize them, and to make conclusion on this topic.

Research Projection: The spiritual upbringing in Kazakh family would respond to the present demands if main types of spiritual upbringing in Kazakh family will define, systematize, and provide with training and methodical complex.

\subsection{Research Goals}

1. To define historical and social preconditions of the spiritual upbringing in Kazakh family.

2. To define traditional pedagogical upbringing types in spiritual upbringing in Kazakh family and to express teenagers' views on spirituality.

3. To establish the main ways of the spiritual upbringing in Kazakh family.

4. To give an approval of upbringing teenagers through the spiritual upbringing in Kazakh family.

5. To systematize forms, methods, and content of the spiritual upbringing in Kazakh family.

6. To use the experience of the spiritual upbringing in Kazakh family and to carry out practical experiment. 
The main idea of the research at present is the use of advanced concepts of the spiritual upbringing in Kazakh family with creative influence on forming continuing education system of national upbringing.

\section{The Methodology and the Theory of the Research}

First, the development of person in society, scientists' researches, the problems of the spiritual upbringing in Kazakh family; second, philosophic, historic, social, psychological, pedagogical principles of spiritual upbringing; third, the place of spiritual upbringing in modern society.

The source of the research: the law about education at the Republic of Kazakhstan, complex programs, the official documents about spirituality, scientific cases articles of philosophers, historians, researches of pedagogy about spiritual upbringing, scientific, and pedagogical works of the author, etc.

We had to choose this topic because of failure in educating a sense of conscience in continuing education of the young people. We took as an issue the ways of solving the problems of these contradictions. Nevertheless, the research question based on the scientific concept "Traditional pedagogical education of consciousness in Kazakh families" requires studying the theoretical side and verifying the practical side. Thus, we took the title as "A system of educating of conscience in traditional pedagogical culture of Kazakh families.

\subsection{The Stages of the Research:}

- The First Stage - to define the theme of the problem, to collect materials related to the topic, and to analyze material for special course of research. Historical and conclusive base of the System of Spiritual Upbringing in Traditional Pedagogical Culture of Kazakh Family was defined.

- The Second Stage - the collection of materials on the problem was continued and systematized. The materials necessary for conclusion were analyzed and special course materials were prepared for publishing. The experimental materials were constructed and the experiment was carried out. The following research was used: application, interview medaling, and pedagogical experiment.

- The Third Stage - all the materials were collected; experiment was carried out; methodical offers, programs, and textbooks were written; analyses, systematization, collection of materials, and the results of experiment were introduced.

\subsection{Scientific and theoretical novelty and importance of the research:}

- the methods of spiritual upbringing in Kazakh family were defined;

- the methodical views of upbringing younger to spirituality were defined;

- the mean, the contest, the forms, the methods of spiritual upbringing in Kazakh family were based;

- the methodical supply for forming spiritual upbringing in Kazakh family was made, and it was entered in practice.

\subsection{The practical importance of the research}

The program of special course, textbooks, scientific, and methodical supplies were made for use with spiritual upbringing in Kazakh family.

\subsection{The methods of research}

Pedagogical, ethnical pedagogical, philosophical, psychological, social, economical analysis in research theme.

\subsection{The main principles in the research:}

- The experience of spiritual upbringing in Kazakh family and its place in historical development of nation;

- The project of forming of spiritual upbringing in Kazakh family;

- The contest, the methods and the way of spiritual upbringing in Kazakh family. 


\subsection{The base of the research}

Taraz State Pedagogical Institute and S. Seifullin Kazakh Agro technical University.

\subsection{The content of the dissertation}

Dissertation consists of three chapter, introduction, conclusion, list of literature and applications.

In the introduction, the author considers purpose, actuality, object, subject, aims, projections, main goals and ideas, methodology and theory, scientific and theoretical novelty, practical importance, methods, principles, sources, and stages of the research. The main section is divided into three parts:

1. "The Theoretical Preconditions of Spiritual Upbringing In Traditional Pedagogical Culture of Kazakh Family," where the author considers the methodical and theoretical bases of researching problem, the stages of development of the traditions of spiritual upbringing in Kazakh family and historical, social, and economical preconditions of spiritual upbringing in Kazakh family. Also, the author analyzes works and views about spiritual upbringing in Kazakh family of Kazakh and world famous Scientifics;

2. "The spiritual upbringing in ethnical pedagogical spays" where author considers Kazakh national pedagogic and she describes main principles of forming and development person;

3. "The using of the progressive methods of spiritual upbringing in traditional pedagogical culture of Kazakh family" where the author considers traditions and customs of Kazakh family, the defining of traditional pedagogical upbringing types in spiritual upbringing in Kazakh family and to state teenagers' views on spirituality.

\section{Conclusion}

School holds a special place in the life of society. Having gained the independence, Kazakhstan set the goals even higher to be delivered by schools.

As the results of a study of a special complex course program on "A system of conscience educating in traditional culture of Kazakh families," we can make the following conclusions and suggestions:

1. The history and social conditions of conscience educating in Kazakh families were determined;

2. Different types of traditional pedagogical education in conscience educating and teenagers' point of view on conscience were determined;

3. A draft of educating conscience was made;

4. Having made a concept of teenagers' education on the basis of conscience educating of Kazakh people, we were able to use it in continuing Education;

5. Content, forms and methods of conscience educating in Kazakh families were systematized;

6. The concept of conscience educating in Kazakh families was used and an experiment was carried out.

The results, the effectiveness of our proposed training materials, and a system of conscience educating in traditional culture of Kazakh families were examined. Nevertheless, this question is going to be raised and discussed in the future many times.

Traditions and customs of Kazakh people were open out in the article, carried out on the basis of the written heritage, used in the upbringing of the younger generation in the spirit of national patriotism; identified and systematized kinds of spiritual education in the Kazakh family, specified and used in continuing education, and today used creatively advanced the idea of spiritual development in the Kazakh family. The types of traditional teacher education were defined in spirit development of Kazakh family, identified adolescents' attitude to the spiritual development and the concept of educating the younger generation in the spirit of moral education, and suggested the use of this concept in continuing education.

\section{References}

Boleev K. (1992). Concept of education developing till 2015. Bilim Alemi.

Education Act of Republic of Kazakhstan (1992). District Educational and Methodical Study, 48.

Nazarbayev, N. A. (2005). "Kazakhstan-2030." Message to Kazakh people of President of the Republic of Kazakhstan. Egemen Kazakhstan, 39.

Yesekeshova M.D. (2003). Public program "Cultural legacy." Egemen Kazakhstan, №311- 312, 29.11.2003.

Yesekeshova M.D (2005). Public program “Cultural legacy." Egemen Kazakhstan. №184-188, 16.082005. 